\title{
A Model of Professional Learning Community Promotion based on Kalyanamitta Principles of Opportunity Expansion Schools under Office of Primary Educational Service Area
}

\author{
${ }^{1}$ Chantana Phumma, ${ }^{2}$ Somsak Boonpoo, ${ }^{3}$ Rawing Ruangsanka, ${ }^{4}$ Phrakhrusophonsarophat (Apiwat \\ Thitasaro) \\ 1,2,3,4 Faculty of Education, Mahachulalongkornrajavidyalaya University, Thailand \\ 1'Cyomok@gmail.com, ${ }^{2}$ boonpoo999@ @otmail.com, ${ }^{3}$ billionwings@ hotmail.com, ${ }^{4}$ nok.aroonrad@gmail.com
}

\begin{abstract}
The purposes of this research were 1) to study the current situation and problem of professional learning community of opportunity expansion schools under Office of Primary Educational Service Area, 2) to develop a model of professional learning community promotion based on Kalyanamitta principles of opportunity expansion schools under Office of Primary Educational Service Area, and 3) to propose a model of professional learning community promotion based on Kalyanamitta principles of opportunity expansion schools under Office of Primary Educational Service Area. Mixed methods research was used for research design. Qualitative research was conducted by documentary study from documents, research reports, articles, thesis, and related research including in-depth interview. Model was developed by focus group discussion and data were analyzed by content analysis. Quantitative research was collected by assessment questionnaires in 4 areas consisted of 1) utility, 2) possibility, 3) suitability, 4) correct. Statistics used for data analysis consisted of percentage, mean and standard deviation. Results indicated that 1) the current situation and problem of professional learning community of opportunity expansion schools under Office of Primary Educational Service Area showed the first order was knowledge management, the second order were two aspects of need assessment consisted of shared leadership and learning and professional development, the third order were two aspects of need assessment consisted of shared vision and Kalyanamitta community, and the fourth order were two aspects of need assessment consisted of collaborative working team and supportive structure of professional learning community. 2) A developed model of professional learning community promotion based on Kalyanamitta principles of opportunity expansion schools under Office of Primary Educational Service Area showed overall at the highest level. Utility and correct were showed at the highest levels, whereas suitability and possibility were shown at high levels respectively. 3) A model of professional learning community promotion based on Kalyanamitta principles of opportunity expansion schools under Office of Primary Educational Service Area was develop in 3 components consisted of the first component of introduction, the second component of process guideline, and the third component of results
\end{abstract}

Keywords

Professional Learning Community, Kalyanamitta Principles, Opportunity Expansion Schools

Article Received: 10 August 2020, Revised: 25 October 2020, Accepted: 18 November 2020

\section{Introduction}

In current world, human development is essential to the development of the country. The government has a policy of developing people of all ages by promoting lifelong learning, so that they can acquire knowledge and new skills that can work in a variety of jobs according to employment trends for future adjustment of the learning process and curriculum in connection with the landscape and society by integrating knowledge and morality together in order to facilitate the development of learners in terms of knowledge, skills, learning, problem solving, listening to opinions of others, morality, ethics and good citizenship with an emphasis on cooperation between stakeholders both inside and outside the school. National Education Plan 2017-2036 set learner aspirations, aiming to develop all learners to have 21st Century Learning Features and Skills (3Rs8Cs) include 3Rs and 8Cs [1]. Education systems need to develop in response to change, with teachers as "coaches" who design the learning process and learn to help learners achieve results. It is important that teachers in the 21 st century do not establish themselves as "knowers" but must seek knowledge at the same time as the learner. At the same time, learning in the 21 st century has to transcend "subject matter" to learning. "21st Century Skills" where teachers will design learning, train themselves as a coach (Coach) and facilitate (facilitator) in problem-based learning. Problem-Based Learning (PBL) of students what is the help of teachers in learning management is the teacher learning community for students (Professional Learning Communities: PLC) which it arises from the gathering of teachers to share experiences of their duties [2]. The professional learning community is also an integral part of the quality assurance within the school. According to the 2018 Educational Quality Assurance Ministerial Regulation Policy, the policy of reforming the system of assessment and quality assurance of institutions study and announce early education standards basic education level and basic education level, Special Education Center 2018 of Standard 2, Administrative and Management Process Standards Assessment of standards for teacher and human resources development is an important factor in ensuring the quality of education management meets the established educational standards. Emphasis is placed on professional expertise which requires ongoing development that meets the needs of both the individual and the exchange of knowledge in the form of building a professional learning community [3]. Teacher development with a professional learning community is also relevant to 
the request for having and postponing the new academic standing in accordance with the Criteria of Books of the Office of Kor. Sor Kor. 0206.3 / Wor 21 dated July 5, 2017, requiring teachers to have and request a promotion there must be no less than 50 hours of participation in the Professional Learning Community (PLC) each year, in addition, according to the letter of the Office of Kor.Sor. 0206.7 / Wor 22 dated 5. July 2017 requires teachers to be developed by continue training in courses certified by the Teacher Development Institute in accordance with the academic standards or certified by GTEPC every year, each year not less than 12 - 20 hours and within 5 years must have 100 hours of development hours. If within 5 years of development hours are not 100 hours, the excess of 50 PLC hours in each year can be counted hours of development [4]. The Ministry of Education has expanded educational opportunities and opened schools to expand basic educational opportunities distributed in other provinces is a school under the Primary Educational Service Area Office Teaching from Kindergarten to Grade 3 and some educational institutes provide instruction from Kindergarten to Grade 6, which within the same school have quite a large age difference. Problems arising from teaching and learning are many as well, and at the same time teachers have a wide variety in their major fields can teach both at the elementary and secondary levels. The researcher is directly involved in the provision of school education to expand educational opportunities. Recognizing the importance of teacher professional development with a professional learning community that will be effective for student quality. teachers and schools at the same time. "The school's professional learning community model extends educational opportunities under the Office of the Primary Educational Service Area ".

\section{Research Objectives}

The purposes of this research were 1) to study the current situation and problem of professional learning community of opportunity expansion schools under Office of Primary Educational Service Area, 2) to develop a model of professional learning community promotion based on Kalyanamitta principles of opportunity expansion schools under Office of Primary Educational Service Area, and 3) to propose a model of professional learning community promotion based on Kalyanamitta principles of opportunity expansion schools under Office of Primary Educational Service Area.

\section{Research Method}

\section{A. Research design}

Mixed methods research was used for research design [5]. Qualitative research was conducted by documentary study from documents, research reports, articles, thesis, and related research including in-depth interview. Model was developed by focus group discussion and data were analyzed by content analysis. Quantitative research was collected by assessment questionnaires in 4 areas consisted of 1) utility, 2) possibility, 3) suitability, 4) correct. Statistics used for data analysis consisted of percentage, mean, standard deviation, and need assessment [6].

\section{B. Research process}

Research into the school's professional learning community model, expanding educational opportunities under the Office of the Primary Educational Service Area there are 3 steps to the research process as follows:

Research Process

Research Methods

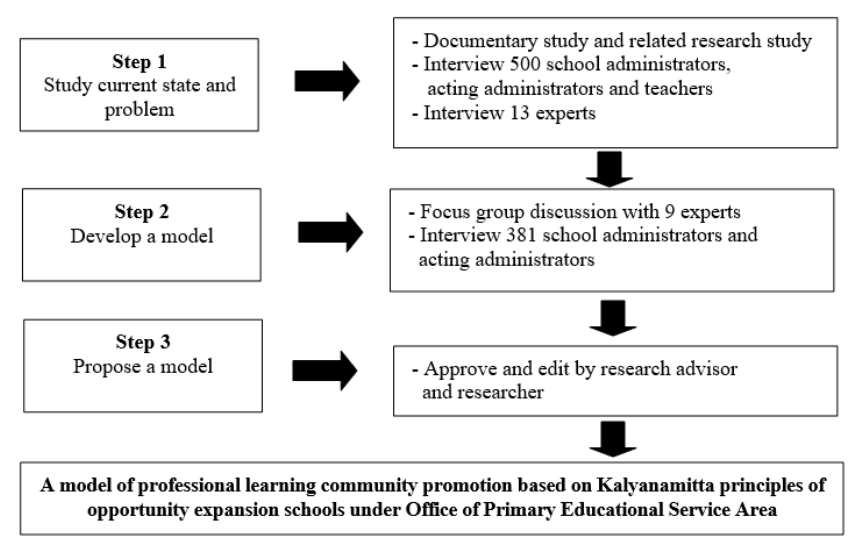

Fig. 1 The research process of the school's professional learning community model, expanding educational opportunities under the Office of the Primary Educational Service Area

From the figure can be described as follows.

Step 1 Study the current conditions and problems of the school's professional learning community, expand educational opportunities. Under the Office of the Primary Educational Service Area Analyze information from documents Relevant research in the country And related research abroad to be used as a research framework create a questionnaire questioned the sample from the multistage randomization method, the respondents were 400 samples from the school director or acting in the position of the school director or teacher, and created a semi-structured interview with 13 experts by purposive sampling, and selection criteria consisting of academics, educational administration, scholars of the professional learning community school director and school teacher expand educational opportunities under the Office of the Primary Educational Service Area The data were analyzed by content analysis, mean, percentage, standard deviation, and need assessment.

Step 2: Develop a professional learning community model according to the school's Kalyanamitta principles, expand educational opportunities under the Office of the Primary Educational Service Area by drafting a professional learning community model according to Kalyanamitta principles from the study of step 1, discussion of the expert group of 9 images / person by selecting a specific model. Analyze data through content analysis. The model was examined by using questionnaires in 4 areas: 1) utility, 2) possibility, 3) suitability, 4) correct, from multi-step randomization informants are education director or acting school director. Schools expand educational opportunities Under the Office of Primary Educational Service Area of 381 persons, the 
statistical analysis was percentage, mean and standard deviation.

Step 3: Propose a model of professional learning community promotion based on Kalyanamitta principles of opportunity expansion schools under Office of Primary Educational Service Area by improving, revising and presenting the school's professional learning community model, expanding educational opportunities Under the Primary Education Service Area Office by an advisor (chairman of the board and director) and the researcher to analyze the data by content analysis.

\section{Results}

1. Current conditions and problems of the school's professional learning community expand educational opportunities. Under the Office of the Primary Educational Service Area the first priority is knowledge management, and second order has two equally important needs: In terms of co-leadership and learning and professional development, the third side had equal needs in two areas: Have a shared vision and the fourth aspect is the Kalayanamit community and there are equal needs in two areas in terms of teamwork, collaboration and structured aspects to support professional learning communities.

2. Development of a professional learning community model according to the school's Kalyanamitta principles to expand educational opportunities under the Office of the Primary Educational Service Area Overall, it is at the highest level. The mean at the highest level was useful accuracy side. The areas with a high average were suitability and possibility aspect.

3. Model of a professional learning community according to the Kalyanamit principles of the school to expand educational opportunities under the Primary Education Service Area Office, consisting of 3 components and results obtained with details as follows:

Component 1: the introductory component has the following main points:

1.1 Principles of the professional learning community

1.2 Objectives of the professional learning community

1.3 Context and feeders of the professional learning community

Component 2: the operational guidelines consisted of 2 parts: the element of promoting the professional learning community according to the Kalyanamit principle. And the process of promoting the professional learning community There is the following essence

2.1 Components for promoting professional learning community according to Kalyanamit principles consist of

1. Composition of a professional learning community

(1) have a common vision

(1) (2) being a united team Is a feature of

(2) have co-leadership

(3) learning and professional development

(4) be a kalyanamit community

(5) there is a structure to support the professional learning community.

(7) knowledge management

2. Kalyanamit

(1). the person who is pretty (Piyo)
(2). person of respect (Khru)

(3). the one who praises (Pawaniyo)

(4). people who know the words (Watta ja)

(5). persons with patience for words (Watjanak khamo)

(6). one who has true knowledge, know deep (Khampi runja Khatang Katta)

(7). one who does not lead to deterioration (Nojatthane Niyoshye).

2.2 the process of promoting the professional learning community consists of 4 processes:

1. supportive structure

2. creating a culture of learning (Learning cultures)

3. leader and agreement building

4. establishing an audit process

Component 3: The result can be presented as shown in Fig.2.

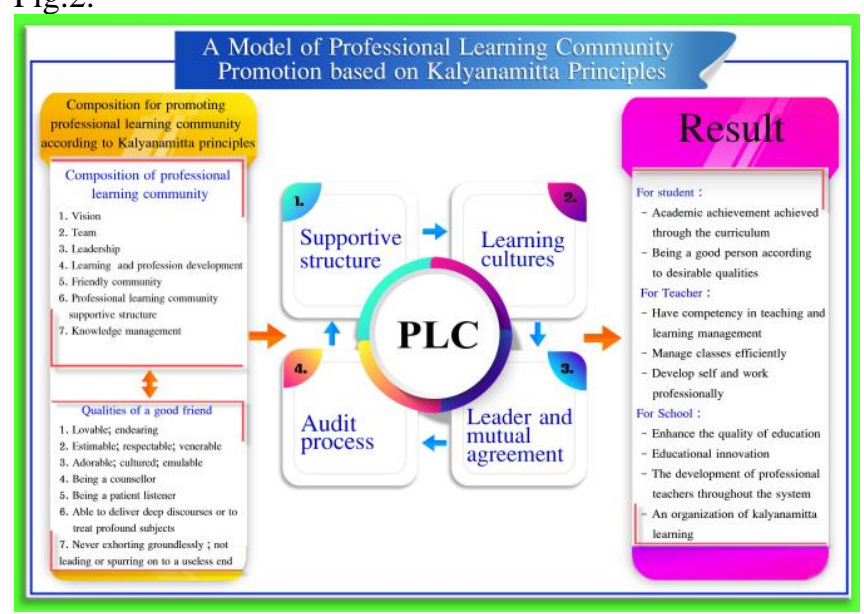

Fig. 2 The model of the school's professional learning community to expand educational opportunities Under the Office of the Primary Educational Service Area

\section{Discussions}

The research on "A model of professional learning community promotion based on Kalyanamitta principles of opportunity expansion schools under Office of Primary Educational Service Area", the researcher brought important points to the discussion as follows.

The results of the research revealed that the professional learning community model according to the Kalyanamit principles of the school extends educational opportunities under the Primary Educational Service Area Office, consisting of 3 components: component 1, the leading part consists of 1.1) principles of the educational learning community. Profession, 1.2) Objectives of the professional learning community, and 1.3) Context of the professional learning community. Component 2: guidelines for the implementation are: 2.1) Composition for promoting the professional learning community according to the Kalyanamit principle, there are 2 parts: 2.1.1 Composition of the professional learning community, 2.1.2 the Kalyanamit principle and 2.2 the process of promoting the professional learning community. Component 3: Effect of the theme it focuses on providing the school with educational opportunities that can be applied to drive the professional learning community in job development and professional development. by applying the principles of 
Kalayanamit and the composition of the professional learning community in which the researcher studies and analyzes the documents. Related research qualified interviews and focus group discussion ask those who are involved in the school, check the format Kalyanamit principle and composition of the Professional Learning Community are elements of promoting the professional learning community according to the Kalyanamit principle. It promotes each other to drive a process for promoting the professional learning community, which consists of 4 processes: 1) Supportive structure is the first process to prepare things, promote the action of the learning community in schools to expand, chance the highlight of this process is the introduction of components of professional learning communities with shared vision and community support structures to design the process. 2) Learning cultures are distinguished in the introduction of community elements. Professional learning, learning and professional development Controlling talking points stimulate questions There is a shared learning process through Share and Learn (Share and Learn) discussion and comment. Voting together best practice choices side as a team of unity shared leadership is fostered by defining the roles of each individual, interchangeably, and all members know their roles. Side is the Kalayanamit community where every teacher must know how to listen. 3) Leadership and agreement building is characterized by bringing together the elements of a professional learning community in the field of leadership. Have co-leadership take action in a variety of ways depending on how the managerial state will give teachers the opportunity to develop individual teacher's leadership. 4) The creation of the audit process has strength in bringing the elements of a professional learning community in knowledge management, taking place within the professional learning community and within each teacher, it is a validation of "what is it," "what is more," "is there more inspiration?" Use it or not and how to use it from the professional learning community. This is because every element of the model is related to the way of life in the work of the present day that teachers, executives and stakeholders work partly. Each person fulfills his duty along with schools expanding educational opportunities, there are differences in teaching and learning at many levels, both at the primary level. Primary and secondary levels teachers of various majors want a model of professional learning community action that is an effective professional development tool a clearer direction and approach, consistent with Gusmash Ade's research, found that the element of the professional learning community in elementary schools is the shared vision and values, collective learning, collaboration, sharing work methods and synergistically reflect structural factors. Social support factors supporting and promoting coleadership [7] is related to Narongrit Intanam's research. It was found that the professional learning community components in schools were: Structure and support norming and shared values cooperation exposure to operational guidance conversations aimed at reflecting performance [8] are related to with Woralak Chukarte's research suggesting that the critical components of the professional learning community, the school context in Thailand with the approach to learning management are consistent with learning knowing in the 21st century consists of 6 areas, namely the Kalayanamit community according to the Thai way, resulting in trust and listening. leadership stimulates potential, creating the manifestation of transformational leaders. Faithful vision contributes to the power of the compass. An open, integrated system is geared towards the learners, creating the manifestation of ownership of the learning task. The professional learning team system to maturity and the spirituality of the teacher create a shared spirit for professional development [9], and a collaborative learning area based on real work, creating a learning culture for change based on real work as each area continues to evolve in this way, it becomes the normal way of the organization. He suggested that the approach to driving learning reform emphasizing the development of teacher professional quality by shifting the budget for teaching professional development through professional organizations with training as the main, turning to budget allocation to facilitate the creation of a professional learning community based on real work that teachers and schools [10].

\section{Recommendations}

\section{A. Recommendations for practices}

From the research results, it was found that current conditions and problems of professional learning community. Schools expand educational opportunities Under the Office of the Primary Educational Service Area Knowledge management. There is a need assessment result in the first order, it should be developed by the school director, and the Primary Educational Service Area Office defined as a qualitative indicator of teacher development promotion in training, development, and exchange of knowledge, or conducting professional learning communities.

\section{B. Recommendations for further research}

1. Should study strategies for community administration, professional learning according to Buddhist principles under the Office of the Education Area to enable the process of promoting the professional learning community to achieve its objectives effectively.

2. Should study paradigm adjustment of professional learning community according to Kalyanamitta principle of the school expanding educational opportunities under the Office of the Primary Education Service Area in order to create a systematic change for teachers, administrators, academic networks and management, and the results that happened to a sustainable corporate culture.

\section{Conclusion}

A professional learning community model based on the Kalayanamit principle is a tool for teacher spiritual development, aiming to work to develop the quality of the learner to be a good person according to desirable characteristics and have academic achievement achieved through the curriculum effectively. 


\section{References}

[1] G. Adae, "Development of a professional learning community model through an action research process cooperative form in elementary school ", Doctor of Philosophy thesis, Graduate School: Burapha University, 2018.

[2] N. Intanam, "The development of principles for building a community Professional learning in school ", Doctor of Education Thesis, Graduate School: Chulalongkorn University, Bangkok, 2010.

[3] P. Leekitwattana. Educational research methods 11th edition revised, Bangkok: Min Service Supply, 2016.

[4] W. Chookarte, "Teacher Professional Learning Community Model for 21st Century Learning, School Context in Thailand", Doctor of Education Thesis. Graduate School: Prince of Songkla University, 2014.

[5] S. Wongwanich, Research needs to be assessed. Bangkok: Chulalongkorn University Press, V.Print (1991) Co., Ltd., 2015.

[6] Office of the Basic Education Commission, Training manual for driving the process of PLC (Professional Learning Community) "Professional learning community" to educational institutions (copy), 2017.

[7] Educational Testing Bureau, Guidelines for quality assessment according to early childhood education standards Basic education level Basic education level, special education center, Community Printing House Agricultural Cooperatives of Thailand Ltd., 2018.

[8] Office of Human Resources and Legal Development, Assessment Manual for Teacher Civil Service and Educational Personnel for Teacher Position and Academic Promotion (Recipe), 2018.
[9] Office of the Education Council Secretariat, National Education Plan 20172036. 1st edition, Bangkok: Prik Wan Graphic Co., Ltd., 2017.

[10] R. Bolam, A. McMahon, L. Stoll, S.Thomas, M.Wallace, A.Greenwood, K.Hawkey, M. Ingram, A. Atkinson, and M.Smoth, Creating and Sustaining Effective Professional Learning Communities, London: University of Bristol, 2005. 